\title{
18
}

\section{IT curriculum in business education content and market analysis ${ }^{1}$}

\author{
K.D. Levin, Tel Aviv College of Management \\ 9 Shoshana Persitz, Tel Aviv, Israel, \\ Phone:972-3-6902055, Fax:972-3-6990454 \\ email:levind@tx.technion.ac.il
}

M. Telem, School of Education, Tel Aviv University

Ramat Aviv, Tel Aviv, Israel,

Phone:972-3-6407123, Fax:972-3-6409477

email: telem@post.tau.ac.il

\begin{abstract}
The purpose of the paper is to examine crucial needs, pedagogical issues and challenges of redesigning and developing courses for training MBA students about the kind of decision problems that they are increasingly called upon to analyse. The paper will view both the "supply side" and the "demand side". The "supply side" refers to the desired course content in terms of balance between theoretical knowledge, domain knowledge and business applications. The "demand side" refers to the corporate recruiting point of view, type of career paths open to graduates in various functional areas like corporate finance, investment banking, manufacturing, marketing and traditional MIS departments.
\end{abstract}

\section{Keywords}

IS curriculum, productivity paradox, end user training, content level analysis.

\footnotetext{
${ }^{1}$ This paper was supported by the research unit, College of Management, Tel Aviv, Israel
} 


\section{INTRODUCTION}

At Theseus in France, French Telecom has founded a business school whose mission is to provide IT - centered MBA education. In Turku, Finland, a Technology Center has been created comprising the computer science and information systems faculties of three universities. The critical mass is exploited in a new information system curriculum for MBA students and business managers. Erasmus University Rotterdam responded to a perceived need by the Dutch business community by creating an innovative MBA curriculum for an International Master of Business Informatics (MBI) program for both junior students and executives. These are only few of the initiatives taking place as a result of the changing needs of both the curriculum and methods of information systems education in business schools.

The problem we see in trying to determine the place of IT in management education is that the impact of IT on success of the business is not clear. We expect that management education will enhance the effectiveness of the students in pursuing organisational goals, and we would like IT education in management to contribute to the success of information systems in pursuing these goals. Although spending on IT has surged in the past decade, there is suprisingly little formal evidence (and conflicting results) linking it to higher productivity. The "productivity paradox " of information systems is that, despite enormous improvements in the underlying technology, the benefits of IS spending have not been found in aggregate output statistics. On one hand several studies by Loveman (1994) and by Barua, Kriebel and Mukhopadhyay (1995) have been unable to reject the hypothesis that computers add nothing at all to total output. On the other hand Brynjolfsson (1993) concludes that the "productivity paradox" disappeared by 1991. The major conclusion of Ahituv and Giladi (1993) is that except for some "war stories" and anecdotes, we know very little about what really contribute to the success of IT in pursuing organisational goals. As long as businesses are asking "where is the payoff?" it is clear that our understanding of the value of IT in organisation is incomplete as well as our understanding of the requirements on IT education in management.

The purpose of the paper is to examine crucial needs, pedagogical issues and challenges of redesigning and developing courses for training MBA students about the kind of decision problems that they are increasingly called upon to analyse. The paper will view both the "supply side" and the "demand side". The "supply side" refers to the desired course content in terms of balance between theoretical knowledge, domain knowledge and business applications. The "demand side" refers to the corporate recruiting point of view, type of career paths open to graduates in various functional areas like corporate finance, investment banking, manufacturing, marketing and traditional MIS departments.

The paper will focus on the extent to which IT education should be integrated with general business education. In section 2 we will present the theoretical framework that will help us to identify the IT components of business activities. The market demand view for IT skills is presented in section 3. Based on the normative view of section 2 and the job market view of section 3 we will discuss the educational needs in section 4 . Some pedagogical issues that relate to these needs will be discussed in section 5 . We will also relate to the following issues: What place does IT education have without its integration with management education? Also, if we need to teach managers about IT, what do we need to teach IT professionals about management? 


\section{THE THEORETICAL FRAMEWORK}

To assess the requirements for IT training within the general business education, we adopted a subset of Ostroff and Ford (1989) "content level" framework. This framework was used by Nelson, Whitney and Philcox (1995) in their assessment of end user training needs. It combines the dual perspectives of content, ie., person, task and organisational (as suggested by Mcgehee and Thayer (1961)) across the various levels of an organisational system, i.e., individual, subunit and organisation-wide level. The intersection of each content factor with each level (a nine cell matrix) suggests questions or issues that should be addressed when analysing training needs in general and assessing IT training requirements in particular.

The subset of "content - level" issues as applied in this paper relates to the first two content areas (person and task) and their intersection with the individual level and the subunit level. Specifically, we address the following questions:

Person $\quad \underline{\text { Task }}$

Individual What IT knowledge and What are the IT knowledge and skill skills do individuals need requirements necessary for the to learn for effective accomplishment of specific tasks? performance?

Sub Unit What IT skill mix is needed What IT activities and technologies for successful job are required for effective task performance within a given performance within a given sub unit? work group?

The reason for applying only a subset of Ostroff and Ford framework (a four cell submatrix instead of the nine cell matrix) is based on the clear distinction between an integrated enterprise level information system and end user systems (developed at the individual and workgroup levels). Although, the general claim is that IT adds value at all levels: individual, group and organisation-wide (enterprise level), the "productivity paradox" suggests that our understanding of the value of IT at the organisational level is incomplete. Furthermore, the application of enterprise level MIS is still part of the centralised MIS department, while, the career paths of most business education graduates do not pass through the MIS department. Our main focus in this paper is how to enhance the effectiveness of task performance of graduates of business programs in the classical functional areas of marketing, finance etc. (and not as IS specialists at the MIS department). Therefore, we will concentrate on IT educational requirements associated with better performance at the individual level and at the sub unit (work group) level.

Addressing the "task" column in this framework will help us to identify the IT components of accomplishing business activities. These IT components that can enhance the accomplishment of business activity can be translated to IT educational needs. Addressing the "person" column relates specifically to these needs and helps us to determine what IT knowledge and skills we should teach in management education programs in order to enhance the effectiveness of the graduates of these programs. Our purpose is to identify the IT components that add value to business activities (both at the individual level and the group level) and to translate them to educational needs. 
A number of researchers have investigated how managers spend their time. Mintzberg (1973) studied the activities of CEO, Stewart (1967) studied $160 \mathrm{mid}$ and senior level executives, Sayles (1964) focused on 75 lower and middle level managers. The results are suprisingly consistent across time, industry and level of managers. Managers are social and spent a major part of their time in various forms of communication. They are constantly attempting to gain information from internal and external sources and they are commonly involved in the analysis of financial data, marketing surveys and results and operational data. They keep track of facts and figures about various entities that are important to the business and they monitor the status and changes in status of those entities. Consequently, we are looking for IT components that can enhance the effectiveness of task performance (at the individual and group level) by:

- Facilitating interpersonal communication.

- Improving the capabilities to gain information (from various sources).

- Facilitating analysis of internal and environmental data.

- Tracking and monitoring the status of business entities.

\section{THE DEMAND SIDE}

A recent study by Ramakrishna, Vijayaraman and Quarstein (1995) claims that the preparation of MBAs in information technology conceptual knowledge and skills is falling short of the need. They surveyed the opinions of 36 executives from organisations that hire MBAs from AACSB (American Assembly of Collegiate School of Business) accredited business school on 56 individual skills/knowledge areas. These executives were asked to indicate "what level should the MBA possess" for each area. They also indicated what they believed "MBAs actually possessed" after their graduation. This survey suggests that MBAs are less than adequately trained in IT subject areas. An analysis of the degree of deficiency (the percent difference of the "should possess" as compared to the "actually possess") reveals that the deficiencies in the IT conceptual knowledge category are higher than those in the skill category. Specifically, the major deficiencies are in the Information Resource Management area (that include topics like: business links to IS, data as a resource, cost justification of IS) and in some miscellaneous topics like Privacy and Security, Ethical Issues, Disaster Preparedness and Legal Aspects of IS.

A study of the "wanted advertisement" for MIS related jobs in 1992, 1993 and 1994 by Prabhakar, Litecky and Arnett (1995), analysed the skills set that were required by these jobs. Accordingly, the demand for newer skills (like networking, windows) is growing at a fast rate while the demand for traditional skills (like mainframe and cobol) has been holding steady. The skills that are in high demand in today's job market are networking skills followed by Unix, PC skills, relational databases, Windows and $\mathrm{C}$.

Changes in the knowledge and skill requirements of information systems positions were examine by Todd, McKeen and Gallupe (1995). They analysed the content of IS job advertisements over the 20 year period 1970 - 1990 for three types of jobs: programmers, system analysts and IS managers. In this paper we are more interested in their intriguing results concerning the market job requirements of system analysts and IS managers.

There is a clear perception that a successful IS professional blends technical knowledge with business knowledge. It is widely advocated that organisational, functional and managerial skills are becoming increasingly important for most IS positions. Contrary to expectations Todd's findings concerning the analyst job requirements shows rising references to technical 
knowledge over the past 20 years. Thus, the analyst position, as reflected in the job ads, appears to have become more technical over time. Overall, the job ads indicate that the analyst's job requires a greater mix of technical skills with a decline in the proportion of ads devoted to business skills. Concerning IS managers, the ads reflect an increasing demand for business skills, but also a suprising increase in the demand for technical skills.

Thus , inspite of the consistent assertion that business and other "soft" skills are of increasing importance to those working in the IS field, there is little evidence to support this assertion. Furthermore, the changes in job requirements (as reflected in the ads) tend to suggest the need for more, technical knowledge, particularly for system analysts. These results raise questions concerning the implicit understanding by academics and other training practitioners of the extended need for business knowledge in the IS profession.

\section{EDUCATIONAL NEEDS}

The "demand side" analysis (section 3), as well as the theoretical framework adopted here (section 2) suggests that all knowledge workers need proficiency in the fundamental tools of personal computing. In order to achieve improved productivity in their task performance in the work place the students should learn to master the IT components of knowledge workers and learn to design and implement productivity enhancements. Course curricula in institutions of higher education should be tailored to meet the demands of the job market for the technical skills. As stated these skills should address the followings:

- Facilitating interpersonal communication - this category of skills is concerned with the creation, storage and display of documents and include word processing, desk top publishing, presentation graphics and electronic communications. At the workgroup level these skills include IT solutions to support cooperative work (like NOTES), collaborative writing systems, the use of electronic bulletin boards and group conferencing systems.

- Improving the capabilities to gain information - by learning to access data stored in organisation databases and access data sources provided by data utilities (on Internet or other networks).

- Facilitating analysis of internal and environmental data - this category of skills include spreadsheet and statistical analysis packages. At the workgroup level these skills should be extended to gain hands on experience with GDSS (group decision support systems).

- Facilitating tracking and monitoring the status of business entities - by developing and maintaining database applications at the individual level. At the workgroup level these skills should be expanded to accommodate controlled and secured access to shared data. Another useful skill in this category include the use of project management packages.

To a large extent, this set of skills is covered in the new Information Systems' 95 Curriculum Model (1994). Specifically, IS95.P0 ( Knowledge Work Software Tool Kit) and IS95.P2 (Personal Productivity with IS Technology) provide a decent coverage of a suit of basic technical skills and we recommend it (with minor modifications) to business students as well.

In addition to the basic technical skills students should have a conceptual knowledge of the way information is used in organisations. This knowledge is covered by the new IS95 curriculum model in the course description of IS95.1 (Fundamentals of Information Systems) and IS95.3 (Information Systems Theory and Practice). The courses provide an understanding of system concepts and how information systems relate to organisations. Topics include 
decision theory and how information is used for decision support in various organisational levels (strategic, tactical and operational).

The IS curriculum, as suggested by the ACM and DPMA (Data Processing Management Association), places a strong emphasis on the importance of managerial and organisational knowledge. Assuming that the evidence cited by Todd et al. (1995) is taken at face value, then, the job market is looking for more technical skills. It is possible that the market demand reflects a recruitment gap in which the recruitment process is misdirecting its attention toward technical skills. However, it is also possible that there is an educational gap that implies that IT educational efforts are misdirected and that the academic community is not responding to market needs. Our opinion is that no matter which one (educational gap or recruitment gap) is the true gap, our students should be armed with technical skills. This position has clear implications for the teaching of IT professionals. Programs unwilling to train their students in technical skills may find their students at a loss in the job market. "There is very strong evidence that people who work with computers earn higher wages" says Lawrence Katz, chief economist at the labor Dept. (Business Week, 1994, p.30). Also, according to Princeton University economist Alan Krueger, people who use computers at work earn $10 \%$ to $15 \%$ more than colleagues in similar occupations who do not use computers. We believe that the basic suit of software tools described in IS95.P0 and IS95.2 will provide the necessary background to compete favourably in such marketplace.

A possible explanation of these results is that they reflect a major shift to end user computing where a lot of IS work is being performed by end users at the individual level and by joint project teams (of end users and IS professionals) at the group level. A straightforward implication is a requirement for effective communication of team members and all those associated with the development and maintenance of information systems. Effective communication can be enhanced by the use of common language. We propose to emphasise the use of symbols, structures and procedures that are common in IS and business analysis. This include the use of Entity Relationships Diagrams (ERD), Data Flow Diagrams (DFD), Data Structure Diagrams (DSD) and familiarity with Business System Planning (BSP), Critical Success Factors, Value Chain and Customer Resource Life Cycle. This common language will facilitate communications between end users and IS professionals and we propose to include it in a revised curriculum of IS95.7 (Analysis and Logical Design) of the new IS95 curriculum model.

To enhance communication, IS professionals should also be educated about the way information technology is changing businesses. Specifically, Electronic Data Interchange (EDI) and electronic markets lead to "vertical information integration" between traditional partners along the value chain. EDI and electronic markets significantly change the way organisations conduct business with their suppliers and customers. Although there are contradicting studies on the value of IT in organisations (as stated in section 1.) there is at least one major study of the impact of EDI at Chrysler corporation Mukhopadhyay et al (1995). According to this study, the total benefits of EDI translates to annual savings of 220 million dollars for the company. The lesson from Chrysler EDI experience is that EDI should be used as the dominant method of communication between buyers and suppliers. In our opinion both IS professionals and MBAs serving as end users should be familiar with EDI and electronic market concepts. This knowledge is covered by the electronic commerce course as described in ISWorld NET on Internet, Ives, Widmeyer, Parks (1995) and we propose its adoption in the IS curriculum as well as in management education curriculum. 


\section{PEDAGOGICAL ISSUES}

There are two major pedagogical issues that we would like to address: the first deals with obsolescence of knowledge and the second with "bias" in computerised systems.

Given the short half-life cycle of software knowledge we face a very fast rate of obsolescence of technical skills. Hands on experience of a software tool taught at the first year may become obsolete when the students graduate. As IT educators we should emphasise functional concepts and tell the students that the "sintax" and "interface" are bound to change in few years. Students must be taught to accept and look forward to changes. They should be able to master the "knowledge of knowledge", meaning that they should be able to seek out (on the information network) in order to find and understand the constantly changing technical skills.

Bias in computer systems may be the result of pre-existing social bias and technical bias as described by Friedman and Nissenbaum (1993). The issue of bias typically arises when system developers determine who will be included in the database and how individuals in the database will be retrieved. When Friedman asks her students to design a computer dating system, some students assume only heterosexual users. When they deal with linked lists and search for matches with a last entered first searched strategy (to gain better efficiency), they unfairly favour those individuals who join the dating system later. On a much larger extent a similar approach was used by American Airlines air reservation system to distort the market. Bias in computer systems may have legal implications and raises some ethical issues. Following Friedman and Kahn (1994) we believe that the social and the technical issues should be linked throughout the IT curriculum in management education as well as IS professional education.

\section{CONCLUSIONS}

In this paper we combined a "content - level" framework and job market analysis to determine the requirements for information technology knowledge and skills. The "content" theoretical framework provided the normative view while the job market analysis highlighted the corporate recruiting practice. This help us to evaluate the desired course content in terms of balance between IT technical skills, conceptual knowledge and business applications. Accordingly, we propose to address 4 subject areas:

- A suit of basic technical skills (covered by IS95.P0 and IS95.P2).

- Conceptual knowledge of IS and organisations (covered by IS95.P1, IS95.P3).

- A common "language". to discuss information and business issues (redesigning IS95.P7 to include ERD, DFD, DSD, BSP, CSF, Value chain and CRLC).

- Technical and Functional aspects of EDI and electronic markets (covered by the electronic commerce course).

A problem that we will have to deal with is how to find time in the curriculum for "stand alone" courses to cover these areas. AACSB is encouraging schools to assimilate IT core topics across a spectrum of courses (AACBS 1992). However, a recent study by Schell (1995) concerning this issue is not supporting this recommendation. Accordingly, our recommendation is to handle these issues in separate courses. 


\section{REFERENCES}

Accreditation Council Policies, Procedures and Standards, 1990-92. American Assembly of Collegiate School of Business (AACSB).

Ahituv and Giladi (1993) Business success and information technology: are they really related? Annual Conference on Management Information Systems, May 1993, Tel Aviv University.

Barua, A., Kriebel, C.H. and Mukhopadhyay, T. (1995) Information technology and business value: an analytic and empirical investigation. Information System Research, March , 1-24.

Brynjolfsson, E. (1993) The productivity paradox of information technology. CACM, 36, 66-77.

Business Week (1994) A special 1994 bonus issue on the information revolution, 1-194.

Friedman, B. and Nissenbaum, H. (1993) Discerning bias in computer system. InterCHI 93 Proceedings, ACM/SIGCHI and IFIP TC.13, 141-142.

Friedman, B. and Kahn, P.H. (1994) Educating computer scientists: linking the social and technical. CACM. 37, 65-70.

Gorgone, J.T., Couger, J.D., Davis, G., Feinstein, D., Kasper, G., Longenecker, H.E. (1994) Information Systems '95 Curriculum Model. Data Base, 25, 5-8.

Ives, B., Widmeyer, G., Parks, M. (1995) The electronic commerce course: an early vision of learning in a networked world. Proceedings of the 16th International Conference on Information Systems, December, 385-386.

Loveman, G. (1994) An assessment of the productivity impact of information technologies Information Technology and the Corporation of the 1990s: Research Studies, MIT press.

McGehee, W. and Thayer, P.W. (1961) Training in business and industry. Wiley, New York.

Mintzberg, H. (1973) The nature of managerial work. Harper and Row, New York.

Mukhopadhyay, T., Kekre, S., Kalathur, S. (1995) Business value of information technology: a study of electronic data interchange. MIS quarterly, 19, 137-156.

Nelson, R. R., Whitener, E.M., Philcox, H.H. (1995) The assessment of end user training needs. $C A C M, 38,27-40$.

Ostroff, C. and Ford, J.K. (1989) Assessing training needs: critical levels of analysis. Training and development in organisations. Jossey-Bass, San Francisco.

Prabhakar, B., Litecky, C., Arnett, K. (1995) Boom times ahead: the MIS job market is up. Journal of System Management, 46, 24-28.

Ramakrishna, H.V., Vijayaraman, B.S., Quarstein, V.A. (1995) Executives speak out on MBAs competency in information technology. Journal of System Management, 46, 14-17.

Sayles, L. (1964) Managerial behaviour: administration in complex organisations. McGraw Hill, New York.

Schell, G.P. (1995) Can information systems concepts be assimilated into non is courses? Computer Personnel, January, 3-10.

Stewart, R. (1967) Managers and their Jobs. MacMillan, New York.

Todd,P.A., McKeen, J.D., Gallupe, R.B. (1995) The evolution of IS job skills: a content analysis of IS job advertisements from 1970 to 1990. MIS quarterly, 19, 1-28. 